\title{
Cultural Inheritance and Development Path of Red First Street
}

\author{
Zhou Enming ${ }^{1}$, Li Kehan ${ }^{2}$ \\ ${ }^{I}$ School of physical education, Sichuan University of Arts and Sciences, Dazhou, Sichuan, China \\ ${ }^{2}$ Sports sciences of education, University putra Malaysia, Selangor, Malaysia \\ a2940255673@qq.com \\ b1004741354@qq.com
}

\begin{abstract}
In 1933, the Fourth Front Army of the red army moved south to liberate Shiqiao ancient town. On the memorial archway of the town, the Red Army engraved the five words "Leninism Street". In 2007, Shiqiao Lenin street was jointly awarded the "folk culture experience area" by UNESCO and China Folk Photographers Association, known as "the first red street in China". This paper studies the cultural inheritance of red first street through the methods of literature, field investigation, textual research, comparative history and logical induction. This paper analyzes the political value, economic value, cultural value and educational value of the cultural inheritance of red first street. It is found that the material culture is not well protected and the non-material culture is not well condensed. This paper puts forward the development path of formulating protection measures, condensing red spirit and building high-quality red tourism routes.
\end{abstract}

Keywords: Red first street, red culture, cultural inheritance

\section{红色第一街文化传承与发展路径研究}

\author{
周恩明 ${ }^{1}$, 李珂瀚 ${ }^{2}$
}

${ }^{1}$ 四川文理学院体育学院, 达州, 四川, 中国

${ }^{2}$ 马来西亚博特拉大学教育学院, 雪兰莪, 马来西亚

a2940255673@qq.com

b1004741354@qq.com

\section{摘要}

1933 年, 红四方面军挥师南下, 解放石桥古镇, 在小镇牌坊上, 红军刻下了 “列宁主义街” 五个字。2007 年, 石桥列宁街被联合国教科文组织和中国民俗摄影家协会联合授予 “民俗文化体验区”，被誉为 “中国红色第一 街”。本文通过文献资料法、实地调查法、考据法、比较史学方法和逻辑归纳法等方法对红色第一街文化传承 进行了研究。分析了红色第一街文化传承的政治价值、经济价值、文化价值和教育价值。发现存在物质文化没 有很好的保护和非物质文化没有很好的凝练的问题。提出制定保护措施、凝练红色精神和打造红色旅游精品路 线的发展路径。

关键词: 红色第一街, 红色文化, 文化传承

\section{1. 前言}

1933 年, 红四方面军挥师南下, 解放石桥古镇, 在小镇牌坊上, 红军刻下了 “列宁主义街” 五个字。 2007 年, 石桥列宁街被联合国教科文组织和中国民
俗摄影家协会联合授予 “民俗文化体验区”，被誉为 “中国红色第一街”。习近平在党史学习教育动员大 会上强调指出, 要教育引导全党大力发扬红色传统, 传承红色基因, 费续共产党人精神血脉, 始终保持革 命者的大无畏奋斗精神, 鼓起迈进新征程、奋进新时 
代的精气神。红色文化形成于革命战争年代, 是以鲜 血和生命为代价换来的，具备重大文化传承价值，对 此我们必须倍加重视。在新的历史发展定位下, 要实 现跨越式发展, 就要深入挖掘现有红色文化资源, 推 动红色文化与实体经济深度融合, 并结合时代要求不 断发展新时代的红色文化 ${ }^{[1]}$ 。

\section{2. 红色第一街文化传承的当代价值}

\section{1 政治价值}

传承红色文化, 是保持政治精神引领的需要。达 州石桥镇现有保存较为完好的清末川东民居街道 11 条。其中一条长 694 米, 拥有 210 间街房的道路, 横 跨 4 座高大恢宏仿木结构石牌坊的街道被称为列宁 主义街。而在这 4 座牌坊上暂刻了近 40 幅红军革命 标语, 现为四川省红色旅游经典景区之一。该景区为 石梯镇人口提供就业岗位百余个, 动态消除“零就业” 家庭, 为达州市脱贫攻坚全面胜利, 小康社会如期建 成的伟大工程贡献了一份力量。也为当地政府宣传红 色文化, 发扬光荣传统文化起到了宣传作用, 达州一 直是革命老区, 红色文化的发源地, 不管是在抗日战 争时期还是国共内战时期达州都涌现出了一批又一 批的革命战士, 将他们的全部都奉献给了抵御外来侵 略和无产阶级的革命斗争中去, 列宁街的故事就是万 千革命事迹中的代表, 不止是在当时起到了凝聚工农 阶级, 宣传马克思主义无产阶级的力量还从侧面粉粹 国民党的阴谋, 让人民群众看到国民党的真正面目, 还一直激励着一代又一代的共产主义接班人, 耳熟能 详的故事, 发生在同一地方不同年代的革命事迹便是 最好的红色教育。

\section{2 经济价值}

达州市列宁街街上拥有 210 间街房, 其中三分之 二都是商铺, 以售卖文艺品和食品为主。活跃了石梯 镇县域经济发展活力。列宁街的商业化发展优化了石 梯镇的产业结构、提供了更多的就业岗位, 促进商业 和城镇互动融合发展。以石梯特色美食 “石梯蒸鱼” 和 “石梯凉粉” 特色菜为招牌的美食店在小镇上发展 了十余家, 各家各味。将“石梯豆干”作为商标注册, 在小镇上建起了加工厂, 成为小镇上具有优势的特色 产业。成为小镇经济支撑, 提高小镇综合竞争实力, 与米城、管村镇形成县域经济链式发展、竞相发展和 协同发展的局面。县域经济链式发展带动的不止是单 一的经济发展, 还有红色文化的传播, 文化的传播与 经济的发展相辅相成, 使得列宁街的红色文化深远持 久历久弥新。

\section{3 文化价值}

2021 年 10 月 29 日, 达州市人民政府市长严卫 东在达州市第五届人民代表大会第一次会议上作 2021 年达州市政府工作报告第二部分未来五年工作
谋划中第（六）条, 提出要打造特色文旅品牌, 提升 现代化达州文化软实力。坚持文化自信和守正创新, 推动文化事业繁荣、文化产业兴盛。达州市将重点打 造 “巴人故里 - 红色达州” 城市名片。加强巴人文化 资源发掘和保护, 加快推进罗家坝、城坝遗址公园及 其博物馆建设, 建成达州非遗陈列馆和巴文化主题展 陈馆, 扩大 “巴风賓韵・水墨达州” 影响力, 建成巴 文化传承创新和旅游发展高地。开展革命文物集中连 片保护利用, 打造一批红色文化村镇、场馆, 培优 “ $3+4+4+10 ”$ 红色旅游产品体系。“ $3+4+4+10 ”$ 红色 旅游产品体系: 整合打造以万源保卫战、宣达战役、 营渠战役为主线的 3 条红色旅游精品线路, 重点提升 通川区神剑园、万源保卫战战史陈列馆、宣汉县巴山 红军公园、达川区石桥古镇 4 大红色旅游经典景区, 深度建设渠县贵福镇、通川区蒲家镇、通川区梓桐镇、 宣汉县清溪镇 4 个红色文化旅游示范镇, 大力培育通 川区碑庙镇千口村等 10 个红色旅游文化村落 ${ }^{[2]}$ 。石 桥镇历史文化悠久，民俗风情纯厚。传统文化有孔明 灯、小丑剧、打花鼓、金钱板、抬花轿、踩高跷等, 其中 “烧火龙” 和 “翻山铰子” 已被确定为省重点非 物质文化遗产。以红色旅游为主体的开发, 极大的带 动了当地的经济发展, 并且使得当地的革命事迹广为 流传, 同时也推动当地的传统文化成为非物质文化遗 产, 可以得到更好得保护以及发展, 并且出现传统文 化与革命历史事迹相结合得多元发展趋势。

\section{4 教育价值}

列宁街现已成为爱国主义教育基地。接待了石桥 镇小学、石桥中学等多所学校和石桥政府、桥湾乡镇 府等政府部门的参观。达州市为提升公共文化服务水 平。践行社会主义核心价值观，加强社会公德、职业 道德、家庭美德、个人品德建设, 弘扬优秀传统文化, 彰显达州城市精神。推进 “六馆一地” 免费开放, 六 馆一地指: 文化馆、图书馆、博物馆、纪念馆、美术 馆、科技馆、爱国主义教育基地。以加快城乡公共文 化设施建设, 推进公共文化服务数字化, 推进公共文 化服务标准化、均等化。在石桥镇小学和石桥中学当 中不定时得还会开展红色主义文化课程, 老师会在新 生入学得时候会将现代多媒体教育技术与红色文化 相结合, 给同学们普及列宁街的历史以及红色历史文 化激发同学们的爱国主义情怀。每个学期还会以列宁 街为主题开展主题班会活动, 进行红色的爱国主义教 育, 让同学们在现在美好生活的基础上也要牢记历史 勿忘初心, 从小就培养同学们的爱国主义情怀, 这种 红色历史文化革命老区的爱国主义教育与现代教育 技术结合会得到更好的发展。

\section{3. 红色第一街文化的范围与传承现状}

\section{1 物质文化}

第一处是位于列宁主义街上近 40 幅红军革命石 刻标语。“打倒国民党统治，建立苏维埃政权” “拥护 
共产党, 活捉田颂尧” “拥护红军, 扩大红军” “工农 兵, 一家人，起来组织苏维埃政府” “平分土地” 等。 这些标语既是红军的战斗口号, 又是川陕苏维埃的战 斗纲领。其中, 二号牌坊印堂上 “列宁” 两个大字格 外吸引人们的目光, 此二字各大一米见方, 楷书繁体, 笔力遒劲, 使人肃然起敬。印堂处还坚着写有三个字, 为 “主义街”, 各约 15 厘米宽。牌坊下方的拱门处, 则刻有“中国工农红军第四方面军第三十军政治部立” 字样。馆中陈列了革命图文和革命历史文物, 以及革 命人物的奋斗历程、光辉业绩和崇高的革命精神。可 以看出在当时那种时代背景下对于打破国民党统治 的决心以及以及拥护红军, 工农一家欣欣向荣的场景, 可以看出共产党领导的队伍才是人民群众的队伍, 才 是为人民群众谋福祉的队伍, 我党的快速发展同样也 离不开人民群众的大力支持。

第二处是位于街上的红军政治部旧址, 至今保存 依然完整。反映了当时被压迫人民, 在共产党领导下 推翻反动势力的故事。该旧址, 坐东向西, 四合院群 体建筑, 建筑面积约 200 平方米, 建于清代。1933 年 8 月-10月, 红四方面军为了进一步扩大苏维埃政 权范围, 对达县进行了攻击占领, 曾在此短暂办公。 此次战役共歼灭川军千余人。是川陕苏区的革命文化 重要遗址。馆内现设有六组陈列图物: 第一组, 南下 东进、扩大苏区; 第二组, 建立工农政权组织; 第三 组, 传播真理, 刻写标语; 第四组, 加强武装, 整训 扩编; 第五组, 运筹帷幄, 决战千里; 第六组, 红军 精神, 千古传承。

\section{2 非物质文化}

红色非物质文化主要包括革命故事、文艺作品、 相关研究著作及其中所体现的革命精神等 ${ }^{[3]}$ 。

革命故事。曾任石桥乡（镇）长的何成才老人介 绍, 当时椠刻 “列宁主义街” 5 个字的红军战士, 身 系绳索, 脚踩石磴, 手执铁锤、堑把, 悬吊在离地一 丈多高的地方操作。由于这道牌坊上的标语板幅大、 字数多, 花的时间也最长, 直至红军撤退时, 还有一 小部分工作未结束。一天, 红军的一位战士还在上面 刻, 川军和地方团练从几条场口和水巷子冲杀进来, 将那位不知姓名的红军战士抓下来, 凶残杀害。除此 之外, 还有以及当时积极参与斗地主斗争的张发仕。 1950 年, 石桥镇一个叫段代贤的大学生牵头, 用石 亳填补、堑子修复等办法, 将石碑一部分标语进行修 复的革命故事。

相关研究著作。据《石桥镇志》记载, 1933 年 冬和 1934 年 7 月, 中国工农红军第四方面军两次攻 占石桥, 建立石桥苏维埃政权, 广泛发动群众打土豪 分田地, 组织工农群众、社会青年和学校教师参加红 军宣传工作。他们在红四方面军三十军政治部的领导 下, 在鲁家坪街（现列宁街）四座牌坊和一些石壁、 墓碑上刻下了标语。

\section{4. 红色第一街文化传承所面临的问题}

\section{1 物质文化没有很好的保护}

第一处是位于列宁主义街上近 40 幅红军革命石 刻标语。石梯石桥镇现在街上的标语并没有做任何的 相关保护措施, 而是直接暴露在外。自 1933 年, 红 军标语镌刻以后, 1950 年有爱国大学生段代贤进行 牵头修复了一部分标语, 2021 年, 列宁街道路经过 了精心打造修复。此次修复工作的设计者和施工单位 采用了手工雕琭的石材尽量保持了列宁街原有的风 貌。同时为了返养归真, 达到以前老街的风貌, 全部 用人工开采的青石板进行还原修复，通过这次改造之 后基本上是回到了原来清代时候修建的格局。物质文 化是历史的见证是时代的象征, 它谱写了一段又一段 人民群众为打破国民党统治的英勇事迹, 更值得被发 扬广大好好的保护，让我们的后代可以通过这些物质 文化感受到现在美好生活的来之不易，也通过这些物 质文化铭记历史。

第二处是位于街上的红军政治部旧址。在疫情之 后, 列宁街面临着与大多数古镇相同的困境, 游客稀 少, 恶性循环之下, 导致街上商家关门闭店, 旧址也 于 2021 年 3 月暂停了参观, 这样游人便越发的稀少。 红色文化是中国文化的命脉, 我相信疫情过后他将会 再次迎来属于它的无上荣光。

\section{2 非物质文化没有很好的凝练}

革命故事。现在革命故事的宣传更多是靠新媒体 宣传。而民众关注度和话题度都在制作精美的大制作 电影和电视剧上。石桥镇的地方革命故事宣传更多的 要靠地方文艺工作者的改编和制作，而现在与此相关 的文艺作品也是屈指可数, 更没有高级别的代表作。 红色文化是中华民族的革命之魂，是人民的信仰之火， 是中华民族 5000 年发展史上的浓墨一笔, 对于非物 质文化我们要取其精华加大宣传, 推出与其相关的革 命作品。

\section{5. 红色第一街文化发展路径研究}

\section{1 制定保护措施}

对于石刻标语的保护, 是一项很难的任务。但是, 参考武夷山摩崖石刻的保护措施。石桥镇的石刻可以 每五年对石刻进行一次描红和苔藓清理。充分利用现 代高新技术, 采用石质风化小, 附着力强, 色彩鲜亮 的新涂料。并采用传统的朱砂和石灰等天然涂料以替 代现代油漆涂料。参考成都锦里石刻的保护措施, 对 石刻的正面设置了玻璃面罩，以减少人为的破坏痕迹。

\section{2 凝练红色精神}

目前, 达州市已成立达州市巴文化研究院, 应在 四川省巴文化研究会等现有学术阵地的基础上, 整合 
各方资源，利用与地方政府、高校和企业合作等多种 形式, 进一步建大建强巴文化学术阵地, 推动巴文化 研究资源向达州聚集; 拓宽学术方向, 既要重点关注 巴文化起源、演进、发展等基础性课题, 也关注巴文 化历史价值的当代挖掘和转化; 强化巴文化资源普查, 牵头组建专业资源普查团队, 制定详实方案, 分期分 批对达州市传统文化资源进行大普查、大调查, 全面 摸清底数, 建立全市传统文化资源数据库, 为开展学 术研究和推动文旅产业发展奠定基础; 活化巴文化宣 传普及, 通过绘画、微视频、涂鸦、展览、教学等多 种形式做活巴文化宣传普及, 充分释放巴文化历史传 承价值、以文化人价值、经济价值和社会价值, 推动 巴文化从理论上进入百姓的生活中、心灵处; 亮化巴 文化成果转化, 以重点项目为牵引, 点亮巴文化璀嗓 光芒, 深化与相关部门、相关机构、相关人才合作, 推出一批有特色有亮点有影响的巴文化社区、巴文化 商业、巴文化文艺。达州作为巴人故里, 川陕革命根 据地老区有着数不尽地革命故事, 我们要将红色革命 文化与巴山文化相结合, 通过现代传播技术让世人皆 知。

\section{3 打造红色旅游精品路线}

2021 年, 达州市政府提出将整合打造以宣达战 役为主线的红色旅游精品线路作为三大线路之一, 而 达川区石桥古镇、列宁公园与红军碑刻石林为该线路 的经典景点。同时, 达州市政府还将达川区石桥古镇 作为四大红色旅游经典景区之一。为了更好的打造列 宁街, 在列宁街打造了红军文化艺术墙, 此举很好的 凝练了红色精神。一共分成十部分, 一是苦难生活。 表现三座大山压迫, 广大劳苦大众的悲惨生活; 二是 革命曙光。列宁主义思想传播, 知识分子觉醒、反抗, 共产主义思想萌芽。三是农民运动, 表现成立农会、 打土豪劣绅的场景; 四是游击战争。表现大革命失败 后, 达县的共产党从事地下活动和开展游击战争的场 面; 五是宣达战役。表现达县的游击队发展壮大成为 游击队, 后被红四方面军收编为红军第三十三军。六 是政权建设; 七是宣传发动; 八是扩大红军。表现人 民群众支持红军、拥护红军、踊跃参加红军的场景; 九是欢送红军; 十是永放光芒。表现各地少先队员接 受红色传统教育, 发扬红军精神, 建设美好生活的场 景。

\section{6. 结论}

红色第一街具有政治价值、经济价值、文化价值 和教育价值, 对达州市当地促进了各方面的发展。具 有以石刻和红军政治部旧址为代表的物质文化, 但物 质文化没有得到很好的保护, 建议制定化学和物理保 护措施。具有以红军战士石刻和大学生修复的革命故 事为代表的非物质文化, 但红军精神没有得到很好的 凝练, 建议融入地方巴文化, 深化巴文化。此外, 石 桥古镇、列宁公园和红军碑刻石林可以一起融入达州 市政府的整合打造宣达战役为主线的红色旅游精品
线路。

\section{项目基金}

本文为四川文理学院 2021 年度关于 “庆祝中国 共产党成立一百周年理论研究校级科研专项” “中国 红色第一街-达州石桥镇列宁街红色文化传承保护与 发展”的阶段性成果之一。

\section{REFERENCES}

[1] Cui Xia. 2021.Study on the inheritance and development path of red culture in Dongying City. Philosophy and culture, 1: 47-53

[2] Zhang Zhicheng, 2021.work report of Dazhou Municipal Government in 2021.http://www.dz169.net/2021/1029/146371.sht ml.2021-10-29.

[3] Liu Zhan, Luo Xiaojie. 2020. Research on red culture aphasia in Tourism English Teaching in higher vocational colleges. Journal of Yanbian Institute of education. 5:133-135. 